\title{
A role for tumor necrosis factor- $\alpha$ in ischemia and ischemic preconditioning
}

\author{
Orla Watters and John J O'Connor
}

\begin{abstract}
During cerebral ischemia, elevation of TNF- $\alpha$ and glutamate to pathophysiological levels may induce dysregulation of normal synaptic processes, leading ultimately to cell death. Previous studies have shown that patients subjected to a mild transient ischemic attack within a critical time window prior to a more severe ischemic episode may show attenuation in the clinical severity of the stroke and result in a more positive functional outcome. Studies with organotypic hippocampal cultures and mixed primary hippocampal cultures have shown that prior incubation with low concentrations of glutamate and TNF- $\alpha$ increase the resistance of neurones to a subsequent insult from glutamate, AMPA and NMDA, while co-exposure of TNF- $\alpha$ and for example AMPA may have neuroprotective effects compared to cultures exposed to excitotoxic agents alone. In addition our work has shown that although glutamate and TNF- $\alpha$ pretreatment induces analogous levels of desensitisation of the intracellular calcium dynamics of neurons under resting conditions and in response to acute glutamate stimulation, their downstream signalling pathways involved in this response do not converge. Glutamate and TNF- $\alpha$ would appear to have opposing effects on resting $\mathrm{Ca}^{2+}$ levels which supports the proposal that they have distinct modes of preconditioning.
\end{abstract}

Keywords: Tumor Necrosis Factor-alpha, ischemia, hippocampus, glutamate, calcium, preconditioning

\section{Introduction}

\section{Stroke and brain function}

As neurons are incapable of storing glucose, they rely on the cardiovascular system and astrocytes to deliver this source of energy. Thus, the depletion of oxygen (hypoxia) and glucose supply to the neuronal tissue during a stroke, will result in inadequate aerobic metabolism and failure of the cells to generate sufficient ATP levels required to meet metabolic demand [1]. Maintenance of $\mathrm{Ca}^{2+}$ homeostasis is lost due to insufficient ATP to fuel extrusion pumps, while the resting membrane potential is also disrupted due to dysfunction of the $\mathrm{Na}^{+} / \mathrm{K}^{+}$ATPase pumps, leading to 'anoxic depolarisation' [2]. The resulting ionic imbalance within the neuronal and glial cells manifests in the development of tissue acidosis [3], cytotoxic oedema and ultimately necrosis [4]. The accumulation of cations in the cytosol contribute to transient depolarisation at the nerve

\footnotetext{
* Correspondence: john.oconnor@ucd.ie UCD School of Biomolecular and Biomedical Science, UCD Conway Institute
of Biomolecular and Biomedical Research, University College Dublin, Belfield, UCD School of Biomolecular and Biomedical Science, UCD Conway Institute
of Biomolecular and Biomedical Research, University College Dublin, Belfield, Dublin 4, Ireland
}

(C) 2011 Watters and O'Connor; licensee BioMed Central Ltd. This is an Open Access article distributed under the terms of the Creative

terminals, which in turn triggers the activation of voltage-sensitive $\mathrm{Na}^{2+}$ channels, amplifying the accumulation of positive charge within the nerve terminal [5]. This increase in membrane potential will be detected by the voltage sensors on the intracellular domain of voltage-dependent $\mathrm{Ca}^{2+}$ channels (VDCC) causing a large influx of $\mathrm{Ca}^{2+}$ into the terminal promoting vesicular release of neurotransmitters and gliotransmitters such as glutamate and/or TNF- $\alpha$ from neuronal/glial cells, respectively [6], which at pathophysiological levels, induce cellular toxicity $[7,8]$. Extracellular levels of glutamate and TNF- $\alpha$ have been shown to remain elevated in the infarct region for hours up to days after a stroke, depending on the severity of the cerebral ischemic event [9-11]. Due to the complex nature of cross-communication between neuronal and glial cells, the contribution of glutamate and TNF- $\alpha$ to neurotoxicity during stroke is intricately interlinked, with both cell types responsible for the excessive elevation of these mediators to pathophysiological levels, by paracrine and/or autocrine signalling [12]. 
TNF- $\alpha$ receptor expression and signal transduction

TNF- $\alpha$ activity is mediated through activation of its surface receptors, found on both neuronal $[13,14]$ and glial cell populations [15], along with endothelial cells of the cerebral vasculature [16]. Two TNF- $\alpha$ receptors have been identified, the low affinity TNFR1 (p55) and the high affinity TNFR2 (p75) receptor [17]. Although the extracellular domains to the TNFRs have a high degree of homology, their intracellular domains do not [18], which accounts for the complex signal transduction pathways and corresponding proposed antagonistic functions of these two receptor subtypes $[17,19]$. TNFRs may exist as pre-aggregated membrane receptor complexes, whereby TNF- $\alpha$ binds to its receptors as a homo-trimeric protein [20], or may form hetero-receptor complexes in response to ligand binding [21]. Upon TNF- $\alpha$ binding, conformational change of the receptors may lead to receptor endocytosis and exposure of its intracellular binding sites for many adaptor proteins. However, it is important to note that receptor shedding from the membrane may also occur, which results in the neutralisation of circulating TNF- $\alpha$ by acting as a 'decoy receptor' [22].

TNF- $\alpha$-receptor-associated factor-2 (TRAF-2) was first identified as a signal transducer molecule for the TNFR2 TNF- $\alpha$ receptor [23]. TRAF-2 can bind directly to the intracellular domain of TNFR2, and switch on numerous signalling cascades which ultimately result in the activation of the the $\mathrm{NF} \kappa \mathrm{B}$ transcription factor. TRAF-2 associates with receptor interacting protein (RIP) which in turn activates IK $\beta$ kinase (IKK $\beta$ ) to phosphorylate the inhibitory subunit of NFkB $(\mathrm{I} \kappa \mathrm{B})$, leading to dissociation of this subunit, freeing the active $\mathrm{NF} \kappa \mathrm{B}$ transcription factor, which dimerises and translocates to the nucleus to mediate gene transcription [24].

Further investigation has revealed a separate role for TRAF-2 in TNFR1 downstream signalling. TNFR1 has been dubbed the 'death receptor' due to the discovery of an intracellular death domain sequence [25]. Upon internalisation of the activated TNFR1 receptor, TNF receptor-associated death domain (TRADD) adaptor molecule associates with its death domain sequence and signals the recruitment of TRAF-2 or RAIDD adaptor protein to its receptor, to initiate downstream activation of cysteine proteases, called caspases, involved in programmed apoptotic cell death. Fas-associated death domain (FADD) can either bind directly to TNFR1 death domain sequence or to the TRAF-2-TRADD complex and induce the auto-cleavage of pro-caspase 8 to its active form [26], while association of TRADD with RAIDD and receptor interacting protein (RIP) activates caspase 2 [27]. See Figure 1 for details.

However, these signalling cascades are not mutually exclusive to the individual receptors [28]. The activation

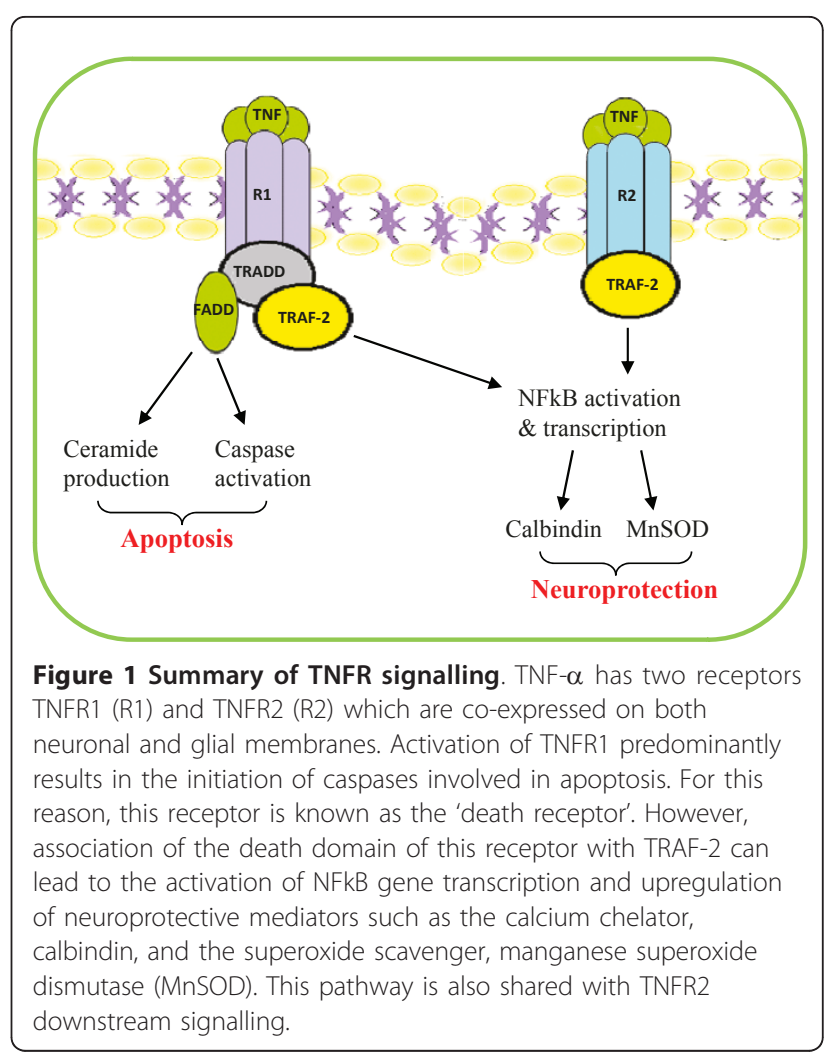

of TRAF-2 by TNFR1 stimulation has also the ability to associate with RIP and initiate NF $\kappa \mathrm{B}$ and JNK signalling leading to a neuroprotective response [29]. TNFRs have also been shown to physically interact with insulin receptor substrate-1 (IRS-1) and PI 3-kinase, which may also contribute to the modulation of NFkB gene transcription [30]. It seems that the rate and persistence of $\mathrm{NF} \kappa \mathrm{B}$ activation differ depending on receptor subtype activated, which may account for the difference in their overall response [19]. A study by Marchetti et al. (2004), using TNFR $1 \%$ and TNFR2 $\%$ KO mice, found TNF- $\alpha$ had a preconditioning effect on subsequent glutamate insult in TNFR $1^{-} \mathrm{KO}$ mice, whereas TNFR $2^{-}$mice were more susceptible to glutamate-induced excitotoxicity. The neurotoxic and neuroprotective effect of TNFR1 and TNFR2, respectively, were further validated using agonistic antibodies for these receptors [19]. This study also found that $\mathrm{NF} \kappa \mathrm{B}$ activity in response to TNFR1 activation was rapid and transient, while TNFR2 activation resulted in a more slower but persistent response. However, as most cell types express both TNFR1 and TNFR2 their receptor activity are not mutually exclusive. Individual receptor signalling may also be confounded by the fact that these receptors may aggregrate as heter-receptor complexes upon binding of TNF- $\alpha$ [21]. Thus the overlap in their signalling cascades adds to the complexity of the overall effect of 
TNF- $\alpha$. It has been postulated that it is the ratio of TNFR1:TNFR2 receptor expression that may govern the overall TNF- $\alpha$ action. These receptors have been shown to be constitutively expressed at different ratios on different cell types, and have been shown to be non-uniformly up-regulated in response to a variety of ligands $[15,31]$.

\section{Contribution of TNF- $\alpha$ to cerebral ischemia}

TNF- $\alpha$ is a well known cytokine involved in the inflammatory response elicited in the region of cerebral ischemia. Indeed, levels of TNF- $\alpha$ may remain elevated in the affected brain tissue for at least $24 \mathrm{~h}$ after an ischemic insult $[9,10]$. However the function of TNF in brain ischemia is controversial. At pathophysiological levels, TNF- $\alpha$ has been shown not only to be involved in necrosis, but also in the regulation of caspases and other apoptotic factors [32,33]. Its initiation of an inflammatory response may result in disruption of the blood-brain barrier, compromising the protective barrier between the brain and the systemic circulation. Thus the infiltration of peripheral inflammatory cells to the affected brain region can occur, exacerbating the overall inflammatory response $[34,35]$. TNF- $\alpha$ has also been shown to stimulate astrocyte [36] and microglial [15] activation and proliferation in a paracrine and/or autocrine fashion.

In early studies with TNF KO mice Mattson showed clearly that damage to neurons by focal cerebral ischemia and excitotoxic insults was enhanced in TNFR-KO mice, implicating TNF as a neuroprotectant in the brain [37]. These effects were shown to involve increased oxidative stress and supression of injury induced microglial activation. Later studies by the same group implicated both TNFRs, namely p 55 and p75 in these effects [38]. More recently Lambertsen et al. (2009) have recently identified a neuroprotective role for microglial dervied TNF in cerebral ischemia an affect shown to be due to TNF-p55R activity [39]. In this work with TNF-p55R KO mice they also reported a reduced microglial population size and interestingly reduced Toll-like receptor 2 expression. The work of Taoufik et al (2008) investigated the molecular mechanisms of the neuroprotective effects of TNF using TNFR1 KO mice using the model of middle cerebral artery occlusion. They found that erythropoietin (originally described as a hematopoietic growth factor) and vascular endothelial growth factor (VEGF) induced neuroprotection against glucose deprivation, NMDA excitotoxicity and oxygen glucose deprivation and that these effects required the presence of TNFR1 [40]. These data together provide stong evidence for that TNF plays a key role in determining the survival of endangered neurons in cerebral ischemia.
Glial cells contain metabotropic type 2 glutamate receptors (mGluR2) on their plasma membrane, which, once activated by excessive glutamate release during cerebral ischemia, results in stimulation of $\mathrm{IP}_{3}$-mediated $\mathrm{Ca}^{2+}$ release from intracellular stores and the release of 'gliotransmitters' such as TNF- $\alpha$, ATP and glutamate itself [41]. TNF- $\alpha$ can act in both an autocrine and a paracrine fashion, stimulating its receptors found on glial and neighbouring neuronal cell membranes. Stimulation of TNFR's present on microglial membranes stimulates the upregulation of glutaminase, an enzyme involved in the conversion of glutamine to its active form, glutamate. Excess glutamate production in the microglia may result in the uncontrolled release of glutamate into the extracellular space via hemichannels present on the microglial membrane [42]. TNF- $\alpha$ can also have negative effects on glutamate uptake and degradation by astrocytes. Activation of the TNFR1-caspase 3 pathway results in the cleavage of EAAT2 at the intracellular C-terminal domain of the glutamate transporter, rendering it inactive [43]. Stimulation of the NFkB pathway in astrocytes by TNF- $\alpha$, decreases the transcription and expression of EAAT2 on the glial membrane, reducing glutamate uptake from the synaptic cleft [44]. Although this response may favour glial survival by preventing overaccumulation of glutamate in the astrocytes, neuronal survival will be further compromised as a result, due to prolonged excitation of these cells by excessive glutamate in the synaptic cleft [45]. TNF- $\alpha$ stimulation of astrocytes may also result in PKC mediated activation of NFkB transcription, and upregulation of interleukin-6, a potent inflammatory mediator, thus exacerbating the inflammatory response [46].

Activation of the TNFR1 receptor on neurons initiates the caspase cascade involved in apoptosis [8] Badiola et al. (2009) using TNFR KO mice and an OGD model in cortical cultures showed that TNF induced apopotic cell death involves TNFR1-activation of caspase- 8 and caspase-3 but not caspase-9 [33]. Neuronal TNFR1mediated $\mathrm{IP}_{3}$ activation may induce the insertion of $\mathrm{Ca}^{2+}$ permeable AMPARs into the post-synaptic density, thus may contribute to $\mathrm{Ca}^{2+}$-mediated cell death in this way, during an ischemic insult [47]. Indeed Stellwagen and his colleagues also found that treatment of hippocampal cultures with TNF- $\alpha(1 \mu \mathrm{g} / \mathrm{ml})$ for 15 min was sufficient to induce a reduction in surface $\mathrm{GABA}_{\mathrm{A}}$ receptors in the same cohort of cells (most likely due to endocytosis), reducing the responsiveness of these cells to inhibitory input, which would further exacerbate excitotoxicity during an ischemic insult [47].

Together, these studies highlight the vast detrimental effects of TNF- $\alpha$ on both glial and neuronal functioning during cerebral ischemia. TNF- $\alpha$ mediated cell destruction may be mediated directly, via activation of its 
TNFR and subsequent cell death signalling pathways, or indirectly by enhancing glutamate excitotoxicity. Overall there is convincing data supporting both detrimental and protective effects of TNF in brain ischemia. Figure 2 summarises some of these processes.

\section{TNF- $\alpha$ and ischemic preconditioning}

A milder form of a cerebral ischemic event, known as a transient ischemic attack (TIA), results in a brief disruption of the cerebral blood supply and temporary presentation of stroke-like symptoms. A TIA may occur upon narrowing or temporary blockage of a cerebral artery by a thrombus or an embolism. A TIA is considered a warning sign that a more severe stroke may occur if appropriate measures are not taken to prevent it. Recent studies have shown that a mild TIA within a narrow time window prior to a stroke may enhance the tolerance of the brain to deal with this second insult. In 2000, a study of 2490 stroke patients, found that a TIA must be at least $5 \mathrm{~min}$ in duration in order to induce neuroprotection [48]. Conversely, a prolonged TIA (greater than one week) or repetitious TIA's cancel out this neuroprotective effect. This study also found that the neuroprotective effect of a TIA is transient, greatly diminishing within $72 \mathrm{~h}$. Interestingly, a clinical study carried out by Castillo et al. (2003) found that plasma levels of TNF- $\alpha$ remained elevated in patients for up to $72 \mathrm{~h}$ after a TIA, and that those who experienced a TIA prior to a stroke within this time window had a better functional outcome than those who did not [49]. Corresponding with the in vivo findings, a study carried out in mixed cortical cultures in vitro found, using brief oxygen and glucose deprivation (OGD) as a model of TIA, that the OGD-induced neuroprotection was also lost within $72 \mathrm{~h}$ [50]. The preconditioning effect of a TIA can also been demonstrated in many experimental models of stroke, both in vivo [51-53] and in vitro [54,55].

Elevation of both glutamate and TNF- $\alpha$ may persist for days after a TIA and contribute to the enhancement of cellular defences against a more severe ischemic insult [56-59]. To date, extensive research has been carried out in order to isolate the proposed mechanisms of ischemic tolerance caused by glutamate or TNF- $\alpha$ elevation as part of a TIA. Incubation of primary neuronal cells with TNF- $\alpha(100 \mathrm{ng} / \mathrm{ml})$ for $48 \mathrm{~h}$, prior to excitotoxic AMPA or NMDA exposure, significantly reduced the peak $\mathrm{Ca}^{2+}$ response induced by these ionotrophic glutamate receptor agonists [60]. As calcium is a well known mediator of cell death, these findings suggest that TNF- $\alpha$ mediated neuroprotection may be as a result of decreasing conductance of these ionotrophic receptors to $\mathrm{Ca}^{2+}$, or reducing their sensitivity to these glutamatergic agents. This study also found that TNF- $\alpha$ induced upregulation of $\mathrm{NFkB}$ gene transcription of neuroprotective mediators such as calbindin, a calcium chelator, and manganese superoxide dismutase (MnSOD), a powerful anti-oxidant which contribute to this neuroprotective response [60]. However, it must be noted that these experiments were carried out in primary neuronal cultures, in the absence of the glial cell population.

A study carried out by Bernardino et al. (2005) used organotypic hippocampal cultures to investigate TNF- $\alpha$ mediated preconditioning against subsequent AMPA exposure [61]. Organotypic hippocampal cultures best represent the synaptic morphology of the hippocampus in vivo, as the circuitry of the hippocampus is maintained and the contribution of the glial cell population to the overall response can taken into account [62]. Incubation of organotypic hippocampal cultures with 1 $\mathrm{ng} / \mathrm{ml}$ TNF- $\alpha$ for $24 \mathrm{~h}$ increased the resistance of the CA 1 pyramidal cells to a subsequent AMPA insult, while co-exposure of TNF- $\alpha$ and AMPA also had a neuroprotective effect compared to cultures exposed to AMPA alone [61]. However, this neuroprotective effect was lost when the concentration of TNF- $\alpha$ was increased to $10 \mathrm{ng} / \mathrm{ml}$, while co-exposure exacerbated AMPA-induced toxicity, revealing a concentrationdependent element to the TNF- $\alpha$ mediated response. We have also shown in our laboratories using organotypic hippocampal slices that attenuation in resting $\mathrm{Ca}^{2+}$ activity and $\mathrm{Ca}^{2+}$ related responsiveness of cells within the hippocampus as a result of glutamate or TNF- $\alpha$ pre-exposure, may contribute to the development of ischemic tolerance [63]. We found that inhibition of the p38 MAP kinase pathway with SB $203580(10 \mu \mathrm{M})$, before and during TNF- $\alpha$ exposure resulted in a complete reversal of TNF- $\alpha$ 's effect on glutamate-induced $\mathrm{Ca}^{2+}$ influx, 24 h post treatment.

In an in vivo study carried out by Sotgiu and colleagues, they showed using a multiple linear regression analysis that there was a positive linear correlation between blood levels of TNF- $\alpha$ (measured 6-20 h poststroke) and the clinical severity of the cerebral ischemic event, supporting these in vitro findings [64]. As a TIA is a much milder form of stroke, it is possible that the lower levels of TNF- $\alpha$ produced during a TIA contribute to induction of neuroprotective mechanisms, while more pathophysiological levels of TNF- $\alpha$ reached during stroke, exacerbate glutamate-mediated excitotoxicity and cell death. Coinciding with this hypothesis, it is possible that the mild elevation of cell death signalling molecules during ischemic preconditioning, such as ceramide and ROS, may trigger the upregulation of neuroprotective mediators, preparing cellular defences against a subsequent more severe ischemic insult $[55,65]$. Stimulation of neuronal TNFR1 receptors during an initial ischemic 


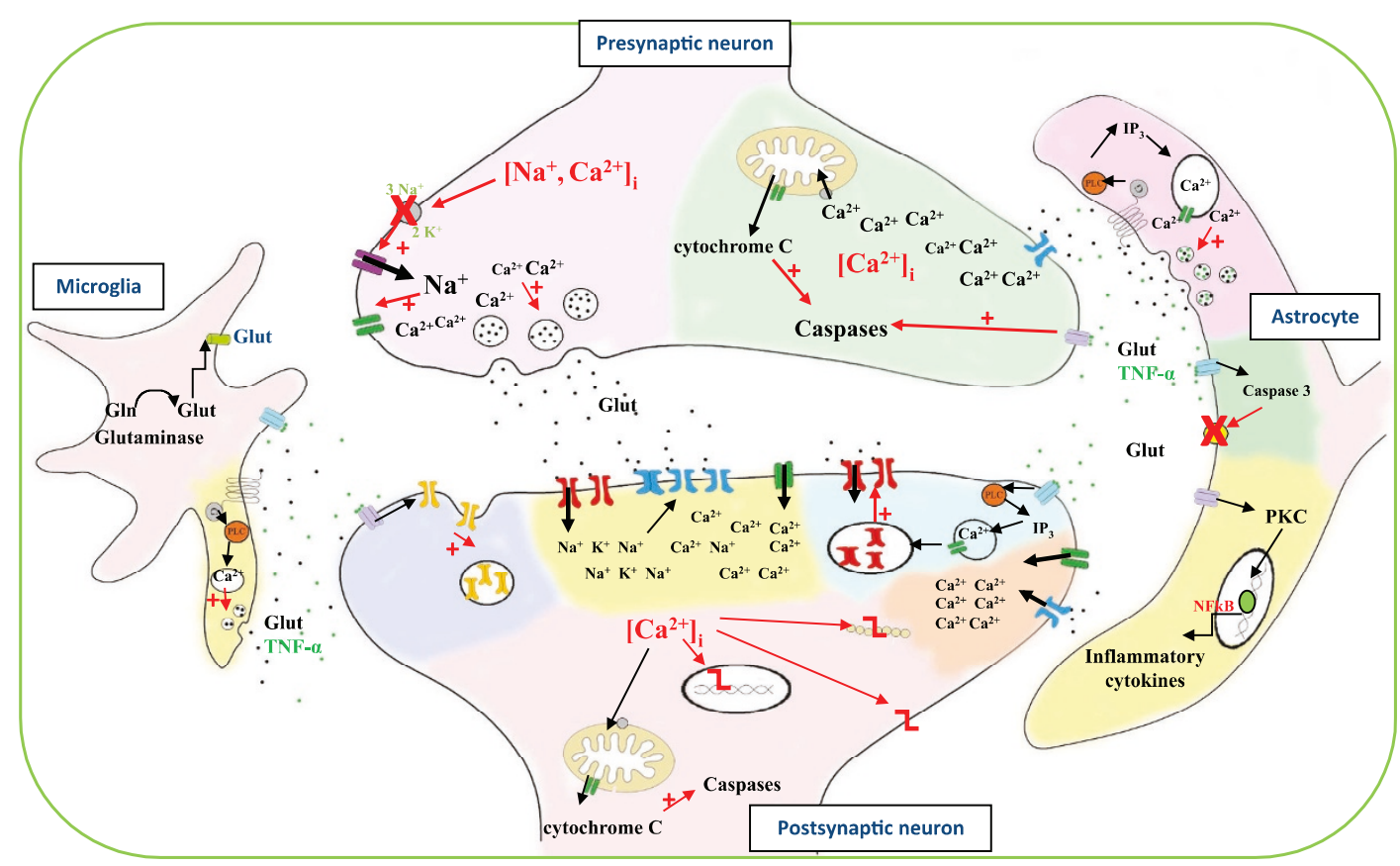

$x \pi$ $x \pi$

Closed / Open NMDAR

VDCC $/ \mathrm{Ca}^{2+}$ channel on ER

TNFR1 / TNFR2

Phospholipase C

Nucleus

Protein

ATPase pump

Inhibition

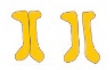

Closed / Open GABA $\mathrm{R}$

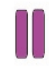

Voltage dependent $\mathrm{Na}^{+}$channel

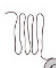

(c) $\mathrm{mGlu} 2 \mathrm{R}$

O

Vesicle

EAAT

Mitochondrion

Hemi-channel

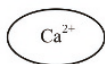

Endoplasmic Reticulum (ER)

$+\quad$ Enhancement of pathway

Destruction of protein / membrane / nuclear material

Figure 2 Summary of the detrimental effects of TNF- $\alpha$ on both neuronal and glial cells during cerebral ischemia. TNF- $\alpha$ synthesis and release for both neuronal and glial cells may be induced via stimulation of mGlu2R by glutamate. TNF- $\alpha$ may then act in an autocrine and/or paracrine fashion, modulating neuronal and glial signalling. Direct stimulation of the TNFR1-caspase 3 pathway results in inactivation of glial EAAT2s, while activation of the NFkB pathway reduces the synthesis and expression of this glutamate transporter. Upregulation of glutaminase in response to microglial TNFR activation also enhances glutamate synthesis and release, elevating levels of this neurotransmitter in the synapse. TNFR1 signalling may also enhance AMPAR trafficking into the postsynaptic membrane, enhancing the sensitivity of the cells to glutamate. Together, these effects result in the exacerbation of glutamate excitotoxicity during cerebral ischemia. 
preconditioning event has been shown to stimulate increased gene transcription and protein expression of EAAT3 on the neuronal membrane, thus priming the neurons to mop up excess glutamate more rapidly and efficiently from the synaptic cleft, reducing the extent of glutamate excitotoxicity which may be induced by a more severe ischemic insult [66].

The contribution of mild acute glutamate elevation during a TIA to the development of ischemic tolerance has also been extensively studied in vitro. During an ischemic event, oxygen and glucose depletion induces neuronal dysfunction and uncontrolled excessive glutamate release. Oxygen and glucose deprivation (OGD) can be induced in vitro by incubating the cultures in an anaerobic chamber with a gas composition of up to $95 \% \mathrm{~N}_{2}$ and $5 \% \mathrm{CO}_{2}$, while replacing the culture media with one which is glucose-free. These conditions were found to mimic those occurring in vivo, by inducing both $\mathrm{Ca}^{2+}$-dependent and $\mathrm{Ca}^{2+}$-independent cell death pathways in both neuronal and glial cell populations [67]. In some cases 2-deoxy-glucose may be added to the glucose free media to inhibit the glycolysis, thus preventing the production of endogenous glucose. In accordance with data obtained from in vivo studies, a short exposure of cultured cells to OGD (10$30 \mathrm{~min}$ ) mimics the events of a TIA, inducing neuroprotection against a subsequent more severe insult [50]. As OGD induces endogenous glutamate elevation, the increased activity of this excitatory neurotransmitter at its receptors was hypothesised as one of the contributing factors to the development of ischemic tolerance. Indeed, Grabb and Choi (1999) discovered that exposure of the cultures with brief exposure to a mild concentration of glutamate (10-30 $\mu \mathrm{M}, 30 \mathrm{~min})$ induced a similar level of neuroprotection against a more prolonged OGD insult applied $24 \mathrm{~h}$ later. This effect was also replicated using sublethal NMDA exposure (5-10 $\mu \mathrm{M}, 30 \mathrm{~min})$ as a preconditioning agent, while inhibition of NMDAR's during OGD abolished the neuroprotective response, suggesting that glutamate-mediated neuroprotection as a result of NMDAR activation [50]. Activation of NMDAR's during glutamate preconditioning has been shown to induce $\mathrm{Ca}^{2}$ ${ }^{+}$-mediated activation of various signalling pathways involved in upregulation neuroprotective mediators $[58,68]$. Pharmacological dissection of the signalling cascades known to the activated by $\mathrm{Ca}^{2+}$, using a variety of antagonists revealed that $\mathrm{Ca}^{2+}$-mediated activation CaMK-II which in turn phosphorylates CREB, inducing CRE-mediated gene transcription of Bcl-2, a protein known to suppress apoptosis. This effect was further validated in vivo using temporary middle cerebral artery occlusion (mCAO) to induce TIA-like elevation in glutamate transmission [68]. Ischemic tolerance induced by OGD may also involve activation of other glutamate receptor types such as the ionotrophic AMPAR and the metabotrophic receptor mGluR1, as antagonism of these receptors was found to attenuate OGD-mediated preconditioning to a subsequent severe OGD insult, in organotypic hippocampal cultures [69].

It is important to note that TNF- $\alpha$ and glutamate share numerous downstream signalling pathways such as CREB, NFkB and MAPK, thus their contribution to the development of ischemic tolerance during a TIA may overlap [59,68,70-73]. Indeed, glutamate itself can stimulate the release of pro-inflammatory cytokines such as TNF- $\alpha$. Keeping this in mind, it is possible that application of exogenous glutamate may have a knock-on TNF- $\alpha$ mediated effect, adding a layer of complexity to the interpretation of experimental findings [74].

\section{Conclusions}

Like many neurological disorders an imbalance in neurotransmission and inflammatory responses within the brain may negatively affect neuronal function, and in more severe cases may result in cell death. Excessive glutamate signalling during cerebral ischemia has been implicated in the development of excitotoxicity, while hightened TNF- $\alpha$ signalling mediates an inflammatory response which is known to exacerbate this detrimental glutamate response. However, mild elevation of glutamate and TNF- $\alpha$ during an acute TIA has highlighted their role as preconditioning stimuli, inducing an endogenous neuroprotective response against subsequent ischemic insults. Numerous pathways and effector molecules are involved in this enhanced tolerance, ultimately resulting in a more stringent regulation of neuronal signalling and calcium responses to excessive glutamate stimulation, induced under conditions of cerebral ischemia.

\section{List of Abbreviations}

(AMPAR): 2-amino-3-(5-methyl-3-oxo-1,2- oxazol-4-yl) propanoic acid receptor; (ATP): adenosine tri-phosphate; (ATPase): adenosine triphosphatase; (BCl-2): B cell lymphoma 2; $\left(\mathrm{Ca}^{2+}\right)$ : calcium; (CAM-KII): calcium/ calmodulin -dependent protein kinase 2; (CREB): CAMP response element binding protein; (EAAT): excitatory amino acid transporter; (FADD): fasassociated death domain; (GD): glucose deprivation; (GABA): $\gamma$-aminobutyric acid; (IkB): inhibitor of kB; (IKKB): inhibitor of nuclear factor kappa-B kinase subunit beta; $\left(\mathrm{IP}_{3}\right)$ : inositol triphosphate; $(\mathrm{IRS})$ : insulin receptor substrate; (JNK): c-Jun N-terminal kinase; (KO): knock-out; (MAPK): mitogen-activated protein kinase; (mCAO): middle cerebral artery occlusion; (mGluR): metabotrophic glutamate receptor; (MnSOD): manganese superoxide dismutase; (NFkB): nuclear factor kappa B; (NMDA): N-Methyl-D-aspartic acid; (OGD): oxygen and glucose deprivation; (PI-3): phosphoinositide- 3; (RAIDD): RIP-associated ICH-1 homologous protein with a death domain; (RIP): receptor interacting protein; (SB203580): 4-[5-(4-Fluorophenyl)-2-[4(methylsulfonyl)phenyl]-1H-imidazol-4-yl]pyridine; (TIA): transient ischemic attack; (TNF-a): tumour necrosis factor-alpha; (TNFR): tumour necrosis factoralpha receptor; (TRAF): TNF-a receptor-associated factor; (TRADD): TNF-a 
receptor-associated death domain; (VDCC): voltage-dependent calcium channel.

\section{Acknowledgements}

We would like to thank Science Foundation Ireland (SFI; 09/RFP/NES2450) and University College Dublin for financial support.

\section{Authors' contributions}

OW participated in the design of the study, carried out the organotypic and primary hippocampal culture studies referred to in the manuscript, performed the statistical analysis and drafted the manuscript. JOC conceived the study, and participated in its design and coordination and helped to draft the manuscript. Both authors read and approved the final manuscript.

\section{Competing interests}

The authors declare that they have no competing interests.

Received: 3 June 2011 Accepted: 2 August 2011

Published: 2 August 2011

\section{References}

1. Suyama K: Changes of neuronal transmission in the hippocampus after transient ischemia in spontaneously hypertensive rats and the protective effects of MK-801. Stroke 1992, 23:260-266.

2. Jarvis CR, Anderson TR, Andrew RD: Anoxic depolarization mediates acute damage independent of glutamate in neocortical brain slices. Cereb Cortex 2001, 11:249-259.

3. Kohno K, Hoehn-Berlage M, Mies G, Back T, Hossmann KA: Relationship between diffusion-weighted MR images, cerebral blood flow, and energy state in experimental brain infarction. Magn Reson Imaging 1995, 13:73-80.

4. Rosenberg GA: Ischemic brain edema. Prog Cardiovasc Dis 1999, 42:209-216.

5. Barber PA, Auer RN, Buchan AM, Sutherland GR: Understanding and managing ischemic stroke. Can J Physiol Pharmacol 2001, 79:283-296.

6. Martin RL, Lloyd HGE, Cowan Al: The early events of oxygen and glucose deprivation: setting the scene for neuronal death? Trends in Neurosciences 1994, 17:251-257.

7. Ankarcrona M, Dypbukt JM, Bonfoco E, Zhivotovsky B, Orrenius S, Lipton SA Nicotera P: Glutamate-induced neuronal death: a succession of necrosis or apoptosis depending on mitochondrial function. Neuron 1995, 15:961-973.

8. Kogo J, Takeba Y, Kumai T, Kitaoka Y, Matsumoto N, Ueno S, Kobayashi S: Involvement of TNF-alpha in glutamate-induced apoptosis in a differentiated neuronal cell line. Brain Res 2006, 1122:201-208.

9. Liu T, Clark RK, McDonnell PC, Young PR, White RF, Barone FC, Feuerstein GZ: Tumor necrosis factor-alpha expression in ischemic neurons. Stroke 1994, 25:1481-1488.

10. Bullock R, Zauner A, Woodward J, Young HF: Massive persistent release of excitatory amino acids following human occlusive stroke. Stroke 1995 26:2187-2189

11. Davalos A, Castillo J, Serena J, Noya M: Duration of glutamate release after acute ischemic stroke. Stroke 1997, 28:708-710.

12. Ventura R, Harris KM: Three-Dimensional Relationships between Hippocampal Synapses and Astrocytes. The Journal of Neuroscience 1999, 19:6897-6906.

13. Dziewulska D, Mossakowski MJ: Cellular expression of tumor necrosis factor a and its receptors in human ischemic stroke. Clin Neuropathol 2003, 22:35-40.

14. Figiel I, Dzwonek K: TNF[alpha] and TNF receptor 1 expression in the mixed neuronal-glial cultures of hippocampal dentate gyrus exposed to glutamate or trimethyltin. Brain Research 2007, 1131:17.

15. Dopp JM, Mackenzie-Graham A, Otero GC, Merrill JE: Differential expression, cytokine modulation, and specific functions of type-1 and type-2 tumor necrosis factor receptors in rat glia. J Neuroimmunol 1997, 75:104-112.

16. Bebo BF Jr, Linthicum DS: Expression of mRNA for $55-k D a$ and $75-k D a$ tumor necrosis factor (TNF) receptors in mouse cerebrovascular endothelium: effects of interleukin-1 beta, interferon-gamma and TNFalpha on cultured cells. J Neuroimmunol 1995, 62:161-167.
17. Tartaglia LA, Weber RF, Figari IS, Reynolds C, Palladino MA Jr, Goeddel DV: The two different receptors for tumor necrosis factor mediate distinct cellular responses. Proc Natl Acad Sci USA 1991, 88:9292-9296.

18. Dembic Z, Loetscher H, Gubler U, Pan YC, Lahm HW, Gentz R, Brockhaus M, Lesslauer W: Two human TNF receptors have similar extracellular, but distinct intracellular, domain sequences. Cytokine 1990, 2:231-237.

19. Marchetti L, Klein M, Schlett K, Pfizenmaier K, Eisel UL: Tumor necrosis factor (TNF)-mediated neuroprotection against glutamate-induced excitotoxicity is enhanced by $\mathrm{N}$-methyl-D-aspartate receptor activation. Essential role of a TNF receptor 2-mediated phosphatidylinositol 3kinase-dependent NF-kappa B pathway. J Biol Chem 2004 279:32869-32881.

20. Chan FK, Chun HJ, Zheng L, Siegel RM, Bui KL, Lenardo MJ: A domain in TNF receptors that mediates ligand-independent receptor assembly and signaling. Science 2000, 288:2351-2354

21. Pinckard JK, Sheehan KC, Schreiber RD: Ligand-induced formation of p55 and p75 tumor necrosis factor receptor heterocomplexes on intact cells. J Biol Chem 1997, 272:10784-10789.

22. Pinckard JK, Sheehan KC, Arthur CD, Schreiber RD: Constitutive shedding of both p55 and p75 murine TNF receptors in vivo. J Immunol 1997, 158:3869-3873.

23. Rothe M, Wong SC, Henzel WJ, Goeddel DV: A novel family of putative signal transducers associated with the cytoplasmic domain of the 75 kDa tumor necrosis factor receptor. Cell 1994, 78:681-692.

24. Song HY, Regnier CH, Kirschning CJ, Goeddel DV, Rothe M: Tumor necrosis factor (TNF)-mediated kinase cascades: bifurcation of nuclear factorkappaB and c-jun N-terminal kinase (JNK/SAPK) pathways at TNF receptor-associated factor 2. Proc Natl Acad Sci USA 1997, 94:9792-9796.

25. Hsu H, Xiong J, Goeddel DV: The TNF receptor 1-associated protein TRADD signals cell death and NF-kappa B activation. Cell 1995, 81:495-504.

26. Chen G, Goeddel DV: TNF-R1 signaling: a beautiful pathway. Science 2002, 296:1634-1635

27. Pimentel-Muiños FX, Seed B: Regulated Commitment of TNF Receptor Signaling: A Molecular Switch for Death or Activation. Immunity 1999, 11:783-793.

28. MacEwan DJ: TNF receptor subtype signalling: differences and cellular consequences. Cell Signal 2002, 14:477-492.

29. Liu ZG, Hsu H, Goeddel DV, Karin M: Dissection of TNF receptor 1 effector functions: JNK activation is not linked to apoptosis while NF-kappaB activation prevents cell death. Cell 1996, 87:565-576.

30. Reddy SA, Huang JH, Liao WS: Phosphatidylinositol 3-kinase as a mediator of TNF-induced NF-kappa B activation. J Immunol 2000, 164:1355-1363.

31. Botchkina Gl, Meistrell ME, Botchkina IL, Tracey KJ: Expression of TNF and TNF receptors ( $\mathrm{p} 55$ and $\mathrm{p75}$ ) in the rat brain after focal cerebral ischemia. Mol Med 1997, 3:765-781.

32. Schneider-Brachert W, Tchikov V, Neumeyer J, Jakob M, Winoto-Morbach S, Held-Feindt J, Heinrich M, Merkel O, Ehrenschwender M, Adam D, et al: Compartmentalization of TNF receptor 1 signaling: internalized TNF receptosomes as death signaling vesicles. Immunity 2004, 21:415-428.

33. Badiola N, Malagelada C, Llecha N, Hidalgo J, Comella JX, Sabriá J, Rodríguez-Alvarez J: Activation of caspase- 8 by tumour necrosis factor receptor 1 is necessary for caspase-3 activation and apoptosis in oxygen-glucose deprived cultured cortical cells. Neurobiol Dis 2009, 35:438-47

34. Hughes CC, Male DK, Lantos PL: Adhesion of lymphocytes to cerebral microvascular cells: effects of interferon-gamma, tumour necrosis factor and interleukin-1. Immunology 1988, 64:677-681.

35. Tsao N, Hsu HP, Wu CM, Liu CC, Lei HY: Tumour necrosis factor-alpha causes an increase in blood-brain barrier permeability during sepsis. $J$ Med Microbiol 2001, 50:812-821.

36. Selmaj K, Farooq M, Norton W, Raine C, Brosnan C: Proliferation of astrocytes in vitro in response to cytokines. A primary role for tumor necrosis factor. The Journal of Immunology 1990, 144:129-135.

37. Bruce AJ, Boling W, Kindy MS, Peschon J, Kraemer PJ, Carpenter MK, Holtsberg FW, Mattson MP: Altered neuronal and microglial responses to excitotoxic and ischemic brain injury in mice lacking TNF receptors. Nat Med 1996, 2:788-94. 
38. Gary DS, Bruce-Keller AJ, Kindy MS, Mattson MP: Ischemic and excitotoxic brain injury is enhanced in mice lacking the p55 tumor necrosis factor receptor. J Cereb Blood Flow Metab 1998, 18:1283-7.

39. Lambertsen $\mathrm{KL}$, Clausen $\mathrm{BH}$, Babcock AA, Gregersen $\mathrm{R}$, Fenger $\mathrm{C}$, Nielsen HH, Haugaard LS, Wirenfeldt M, Nielsen M, Dagnaes-Hansen F, Bluethmann H, Faergeman NJ, Meldgaard M, Deierborg T, Finsen B: Microglia protect neurons against ischemia by synthesis of tumor necrosis factor. J Neurosci 2009, 29:1319-30.

40. Taoufik E, Petit E, Divoux D, Tseveleki V, Mengozzi M, Roberts ML, Valable S, Ghezzi P, Quackenbush J, Brines M, Cerami A, Probert L: TNF receptor I sensitizes neurons to erythropoietin- and VEGF-mediated neuroprotection after ischemic and excitotoxic injury. Proc Natl Acad Sci USA 2008, 105:6185-90

41. Perea G, Araque A: Synaptic regulation of the astrocyte calcium signal. $J$ Neural Transm 2005, 112:127-135.

42. Takeuchi H, Jin S, Wang J, Zhang G, Kawanokuchi J, Kuno R, Sonobe Y, Mizuno T, Suzumura A: Tumor necrosis factor-alpha induces neurotoxicity via glutamate release from hemichannels of activated microglia in an autocrine manner. J Biol Chem 2006, 281:21362-21368.

43. Boston-Howes W, Gibb SL, Williams EO, Pasinelli P, Brown RH Jr, Trotti D: Caspase-3 cleaves and inactivates the glutamate transporter EAAT2. J Biol Chem 2006, 281:14076-14084.

44. Sitcheran R, Gupta P, Fisher PB, Baldwin AS: Positive and negative regulation of EAAT2 by NF-kappaB: a role for N-myc in TNFalphacontrolled repression. Embo J 2005, 24:510-520.

45. Zou JY, Crews FT: TNF alpha potentiates glutamate neurotoxicity by inhibiting glutamate uptake in organotypic brain slice cultures: neuroprotection by NF kappa B inhibition. Brain Res 2005, 1034:11-24.

46. Sparacio SM, Zhang Y, Vilcek J, Benveniste EN: Cytokine regulation of interleukin- 6 gene expression in astrocytes involves activation of an NFkappa B-like nuclear protein. J Neuroimmunol 1992, 39:231-242.

47. Stellwagen D, Beattie EC, Seo JY, Malenka RC: Differential regulation of AMPA receptor and GABA receptor trafficking by tumor necrosis factoralpha. J Neurosci 2005, 25:3219-3228.

48. Moncayo J, de Freitas GR, Bogousslavsky J, Altieri M, van Melle G: Do transient ischemic attacks have a neuroprotective effect? Neurology 2000, 54:2089-2094.

49. Castillo J, Moro MA, Blanco M, Leira R, Serena J, Lizasoain I, Davalos A: The release of tumor necrosis factor-alpha is associated with ischemic tolerance in human stroke. Ann Neurol 2003, 54:811-819.

50. Grabb MC, Choi DW: Ischemic tolerance in murine cortical cell culture: critical role for NMDA receptors. J Neurosci 1999, 19:1657-1662.

51. Barone FC, White RF, Spera PA, Ellison J, Currie RW, Wang X, Feuerstein GZ: Ischemic preconditioning and brain tolerance: temporal histological and functional outcomes, protein synthesis requirement, and interleukin-1 receptor antagonist and early gene expression. Stroke 1998, 29:1937-1950, discussion 1950-1931.

52. Kitagawa K, Matsumoto M, Tagaya M, Hata R, Ueda H, Niinobe M, Handa N, Fukunaga R, Kimura K, Mikoshiba K, et al: 'Ischemic tolerance' phenomenon found in the brain. Brain Res 1990, 528:21-24.

53. Matsushima K, Hakim AM: Transient forebrain ischemia protects against subsequent focal cerebral ischemia without changing cerebral perfusion. Stroke 1995, 26:1047-1052.

54. Pringle AK, Thomas SJ, Signorelli F, lannotti F: Ischaemic pre-conditioning in organotypic hippocampal slice cultures is inversely correlated to the induction of the 72 kDa heat shock protein (HSP72). Brain Res 1999, 845:152-164

55. Liu J, Ginis I, Spatz M, Hallenbeck JM: Hypoxic preconditioning protects cultured neurons against hypoxic stress via TNF-alpha and ceramide. Am J Physiol Cell Physiol 2000, 278:C144-153.

56. Wang X, Li X, Erhardt JA, Barone FC, Feuerstein GZ: Detection of tumor necrosis factor-alpha mRNA induction in ischemic brain tolerance by means of real-time polymerase chain reaction. J Cereb Blood Flow Metab 2000, 20:15-20.

57. Saha RN, Liu X, Pahan K: Up-regulation of BDNF in astrocytes by TNFalpha: a case for the neuroprotective role of cytokine. J Neuroimmune Pharmacol 2006, 1:212-222.

58. Lin $\mathrm{CH}$, Chen PS, Gean PW: Glutamate preconditioning prevents neuronal death induced by combined oxygen-glucose deprivation in cultured cortical neurons. Eur J Pharmacol 2008, 589:85-93.
59. Saha RN, Ghosh A, Palencia CA, Fung YK, Dudek SM, Pahan K: TNF-alpha preconditioning protects neurons via neuron-specific up-regulation of CREB-binding protein. J Immunol 2009, 183:2068-2078.

60. Glazner GW, Mattson MP: Differential effects of BDNF, ADNF9, and TNFalpha on levels of NMDA receptor subunits, calcium homeostasis, and neuronal vulnerability to excitotoxicity. Exp Neurol 2000, 161:442-452.

61. Bernardino L, Xapelli S, Silva AP, Jakobsen B, Poulsen FR, Oliveira CR, Vezzani A, Malva JO, Zimmer J: Modulator effects of interleukin-1beta and tumor necrosis factor-alpha on AMPA-induced excitotoxicity in mouse organotypic hippocampal slice cultures. J Neurosci 2005, 25:6734-6744.

62. De Simoni A, Griesinger CB, Edwards FA: Development of rat CA1 neurones in acute versus organotypic slices: role of experience in synaptic morphology and activity. J Physiol 2003, 550:135-147.

63. Watters $\mathrm{O}$, Pickering $\mathrm{M}, \mathrm{O}^{\prime}$ Connor JJ: Preconditioning effects of tumor necrosis factor-alpha and glutamate on calcium dynamics in rat organotypic hippocampal cultures. J Neuroimmunol 2011, 234:27-39.

64. Sotgiu S, Zanda B, Marchetti B, Fois ML, Arru G, Pes GM, Salaris FS, Arru A, Pirisi A, Rosati G: Inflammatory biomarkers in blood of patients with acute brain ischemia. Eur J Neurol 2006, 13:505-513.

65. Wilde GJ, Pringle AK, Sundstrom LE, Mann DA, lannotti F: Attenuation and augmentation of ischaemia-related neuronal death by tumour necrosis factor-alpha in vitro. Eur J Neurosci 2000, 12:3863-3870.

66. Pradillo JM, Hurtado O, Romera C, Cardenas A, Fernandez-Tome P, AlonsoEscolano D, Lorenzo P, Moro MA, Lizasoain I: TNFR1 mediates increased neuronal membrane EAAT3 expression after in vivo cerebral ischemic preconditioning. Neuroscience 2006, 138:1171-1178.

67. Goldberg MP, Choi DW: Combined oxygen and glucose deprivation in cortical cell culture: calcium-dependent and calcium-independent mechanisms of neuronal injury. J Neurosci 1993, 13:3510-3524.

68. Mabuchi T, Kitagawa K, Kuwabara K, Takasawa K, Ohtsuki T, Xia Z, Storm D, Yanagihara T, Hori M, Matsumoto M: Phosphorylation of cAMP response element-binding protein in hippocampal neurons as a protective response after exposure to glutamate in vitro and ischemia in vivo. $J$ Neurosci 2001, 21:9204-9213.

69. Werner CG, Scartabelli T, Pancani T, Landucci E, Moroni F, PellegriniGiampietro DE: Differential role of mGlu1 and mGlu5 receptors in rat hippocampal slice models of ischemic tolerance. Eur J Neurosci 2007, 25:3597-3604.

70. Guerrini L, Blasi F, Denis-Donini S: Synaptic activation of NF-kappa B by glutamate in cerebellar granule neurons in vitro. Proc Natl Acad Sci USA 1995, 92:9077-9081.

71. Tamatani M, Che YH, Matsuzaki H, Ogawa S, Okado H, Miyake S, Mizuno T, Tohyama M: Tumor necrosis factor induces $\mathrm{Bcl}-2$ and $\mathrm{Bcl}-\mathrm{x}$ expression through NFkappaB activation in primary hippocampal neurons. J Biol Chem 1999, 274:8531-8538.

72. Irving EA, Barone FC, Reith AD, Hadingham SJ, Parsons AA: Differential activation of MAPK/ERK and p38/SAPK in neurones and glia following focal cerebral ischaemia in the rat. Brain Res Mol Brain Res 2000, 77:65-75.

73. Scholzke MN, Potrovita I, Subramaniam S, Prinz S, Schwaninger M: Glutamate activates NF-kappaB through calpain in neurons. Eur $J$ Neurosci 2003, 18:3305-3310.

74. Chaparro-Huerta V, Rivera-Cervantes MC, Flores-Soto ME, Gomez-Pinedo U, Beas-Zarate C: Proinflammatory cytokines and apoptosis following glutamate-induced excitotoxicity mediated by p38 MAPK in the hippocampus of neonatal rats. J Neuroimmunol 2005, 165:53-62.

doi:10.1186/1742-2094-8-87

Cite this article as: Watters and O'Connor: A role for tumor necrosis factor- $\alpha$ in ischemia and ischemic preconditioning. Journal of Neuroinflammation 2011 8:87. 